\title{
PROPRIEDADES DE COZIMENTO E CARACTERIZAÇÃO FÍSICO- QUÍMICA DE MACARRÃO PRÉ-COZIDO À BASE DE FARINHA INTEGRAL DE QUINOA (Chenopodium quinoa, Willd) E DE FARINHA DE ARROZ (Oryza sativa, L) POLIDO POR EXTRUSÃO TERMOPLÁSTICA
}

\author{
JOÃO TOMAZ DA SILVA BORGES * \\ JOSÉ LUIS RAMIREZ ASCHERI ** \\ DIEGO RAMÍREZ ASCHERI *** \\ RICARDO EUZÉBIO DO NASCIMENTO ***** \\ ARLAN SILVA FREITAS *****
}

\begin{abstract}
A presente pesquisa teve por objetivo analisar as propriedades de cozimento e estudar as características físico-químicas de macarrões pré-cozidos à base de farinha integral de quinoa (Chenopodium quinoa, Willd) e de farinha de arroz (Oryza sativa, L), obtidos por extrusão termoplástica. Os macarrões précozidos, devido às características intrínsecas das matériasprimas, comparados ao macarrão tradicional à base de farinha de trigo apresentaram menores valores para Aumento de Peso (\%), Aumento de volume (\%), Rendimento (\%), Densidade do produto $\mathrm{cru}\left(\mathrm{g} / \mathrm{cm}^{3}\right)$ e altos teores de Sólidos Solúveis (\%). Os resultados deste estudo permitiram constatar que a quinoa integral apresenta maiores valores para as diferentes análises realizadas (composição centesimal aproximada, minerais e aminoácidos). O escore de aminoácidos essenciais para as matérias-primas e macarrões pré-cozidos, conforme recomendações da FAO/WHO (1991), permitiu identificar que a lisina é o aminoácido limitante em ambas as matérias-primas e em macarrões pré-cozidos para crianças de 2 a 5 anos e na farinha de arroz polido e macarrões pré-cozidos para crianças de 10 a 12 anos. Não foi encontrado aminoácido limitante para adultos.
\end{abstract}

PALAVRAS-CHAVE: MACARRÃO SEM GLÚTEN; QUINOA-FARINHA; ARROZFARINHA; EXTRUSÃO TERMOPLÁSTICA.

* Economista Doméstico, Mestre em Ciência e Tecnologia de Alimentos, Universidade Federal Rural do Rio de Janeiro (UFRRJ), RJ (e-mail: jtsborges@yahoo.com.br).

** Eng. de Alimentos, Dr. Tec. de Alimentos, EMBRAPA, Agroindústria de Alimentos, Guaratiba, Rio de Janeiro (e-mail: ascheri@ctaa.embrapa.br).

*** Eng. de Alimentos, Dr. Eng. de Alimentos, Unidade Universitária de Ciências Exatas e Tecnológicas, Universidade Estadual de Goiás (UEG), Anápolis, GO (e-mail: ascheridpr@uol.com.br).

**** Bach. Matemática, EMBRAPA, Agroindústria de Alimentos, Guaratiba, Rio de Janeiro (e-mail: ricardo@ctaa.embrapa.br).

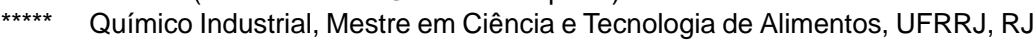
(e-mail: arlanfreitas@yahoo.com.br). 


\section{INTRODUÇÃO}

O processo de extrusão vem ganhando destaque e expansão na indústria alimentícia por apresentar muitas vantagens quando comparado com sistemas tradicionais de processamento. Constitui tecnologia alternativa para o aproveitamento de grande quantidade de produtos e subprodutos, favorecendo a alimentação humana e animal no que diz respeito a misturas enriquecidas por contribuir para a melhoria do valor nutricional dos alimentos. Desta forma, essa tecnologia é de grande interesse para programas de alimentação suplementar em países em desenvolvimento que buscam tecnologia para produção de alimentos nutritivos de baixo custo, destinado às populações mal-nutridas.

A maior parte da população mundial depende de alimentos de origem vegetal como principal fonte nutricional, embora sua qualidade protéica seja inferior aos alimentos de origem animal. Esse fenômeno deve-se principalmente à escassez e ao preço mais elevado da proteína animal. Além disso, muitas pessoas apresentam reações alérgicas a algum componente dos alimentos, o que pode colocar em risco sua saúde, além de reduzir o número de opções no momento da escolha das matérias-primas que irão compor sua dieta diária. Nesse contexto, conforme afirmam MAHAN e SCOTT-STUMP (1998), a doença celíaca ou enteropatia glúten-induzida é um tipo bem conhecido de intolerância alimentar associada especificamente a produtos que contêm glúten (trigo, centeio, cevada, aveia). Os sintomas mais comuns são a diarréia e a desnutrição, decorrentes da má absorção de nutrientes, devido à atrofia da mucosa intestinal. Como conseqüência, o portador da doença perde peso, podendo apresentar diversos sintomas associados à deficiência de vitaminas e minerais. Geralmente é considerada como doença infantil, entretanto os sintomas podem aparecer em qualquer idade. Pequenas quantidades de glúten ou produtos contendo glúten na dieta são suficientes para causar mudanças características na mucosa intestinal, mesmo na ausência de sintomas aparentes. Com a eliminação total do glúten ocorre o reaparecimento das vilosidades e recuperação das capacidades de digestão e absorção da mucosa.

A quinoa (Chenopodium quinoa, Willd) vem despertando a atenção de pesquisadores em várias partes do mundo, devido à sua alta qualidade nutricional. Além disso, a planta apresenta resistência às pragas, tendo 
capacidade para desenvolver-se sob condições adversas de altitude, umidade e em solos pobres em sais minerais (locais em que outros cereais não conseguem se desenvolver) (CHAUHAN e ZILLMAN, 1992). Já o arroz constitui importante fonte de calorias e proteínas na alimentação de mais da metade da população mundial. Apresenta maior digestibilidade, maior valor biológico que outros cereais e elevado quociente de eficiência protéica, apesar de sua deficiência em lisina. Encontra-se entre as mais nutritivas proteínas de cereais, igualandose à aveia e ao centeio (SGARBIERI, 1996).

A quinoa e o arroz são alimentos isentos de glúten, podendo ser consumidos por portadores de doença celíaca sem colocar em risco sua saúde. Entretanto, pouca informação está disponível sobre a mistura dessas matérias-primas na elaboração de produtos alimentícios.

presente trabalho teve como objetivo avaliar as propriedades de cozimento e as características físico-químicas de macarrões précozidos, obtidos a partir da mistura de farinha integral de quinoa e de farinha de arroz polido.

\section{MATERIAL E MÉTODOS}

\subsection{MATÉRIA-PRIMA}

Foram utilizadas farinha integral de quinoa (Chenopodium quinoa, Willd.) e farinha de arroz branco (Oryza sativa, L.) polido, procedentes da Embrapa - Cerrados de Brasília e do comércio, respectivamente. Para a formulação dos macarrões pré-cozidos foram usados, ainda, $1 \%$ de sal refinado (ITA) e 0,50\% de emulsificante (Prêmium).

Para as análises químicas foram empregados reagentes (grau analítico) de diversas procedências (Merck, Ecibra, etc).

\subsection{EQUIPAMENTOS}

No processo de obtenção dos macarrões pré-cozidos e no estudo de suas características físico-químicas foram utilizados os seguintes equipamentos, além das vidrarias, aparelhos e utensílios indispensáveis em laboratório: 
- Agitador de peneiras RO-TAP, modelo RX-29-10, equipado com conjunto de 7 peneiras arredondadas (de 20 a 200 mesh).

- Estufa com circulação de ar, marca Fabbe-Primar.

- Moinho granulador de facas e martelos, TREU, 7,5 cv, com peneira de $1 \mathrm{~mm}$.

- Batedeira industrial SIAM-UTIL S/A, $10 \mathrm{~kg}$.

- Freezer Electrolux/Prosdócimo, modelo H 50C, cod. 06556CBC1.

- Moinho de discos, marca Perten, tipo 3.600, Hz 60, W 750, RPM 1680.

- Balança analítica, marca Mettler Toledo, AG 204.

- Espectrofotômetro de emissão de plasma, ICP spectroflama.

- Cromatógrafo a líquido de alta eficiência (CLAE), Hewlett Packard, $\bmod .1090 \mathrm{M}$.

- Espectrofotômetro Shimadzu UV-190.

- Extrusor Brabender dupla rosca, modelo DSE 45, equipado com resistências elétricas nas quatro zonas ao longo do cilindro, sistema de alimentação, velocidade de rosca controlada em rotações por minuto.

\subsection{PROPRIEDADES DE COZIMENTO DOS MACARRÕES PRÉ- COZIDOS À BASE DE FARINHA INTEGRAL DE QUINOA E DE FARINHA DE ARROZ POLIDO}

Os macarrões pré-cozidos foram submetidos ao teste de cozimento, segundo técnica modificada de CIACCO e CHANG (1986) e LEITÃO et al. (1990), sendo caracterizados quanto ao tempo de cozimento (minutos), aumento de peso (AP\%), aumento de volume (AV\%), sólido solúveis (SS\%), rendimento ( $\mathrm{R} \%)$, densidade do produto cru e cozido $\left(\mathrm{D} \mathrm{g} / \mathrm{cm}^{3}\right.$ ) e acidez alcoólica (AA $\left.\mathrm{mL}\right)$. Os resultados foram comparados aos obtidos com macarrão comercial tipo talharim, à base de trigo, pela similaridade em espessura e largura. Para o cozimento utilizouse relação de massa de macarrão (g):massa de água $(\mathrm{g})$ na proporção de 1:3.

O tempo de cozimento foi determinado após realização de testes preliminares, quando as amostras apresentaram-se altamente flexíveis e com a parte central macia, conforme recomendações de LEITÃO et al. 1974; DEXTER, MATSUO e MORGAN, 1981. 


\subsection{CARACTERIZAÇÃO QUÍMICA DA FARINHA INTEGRAL DE QUINOA, FARINHA DE ARROZ POLIDO E MACARRÕES PRÉ- COZIDOS}

Amostras de macarrões pré-cozidos secos e crus, moídas em moinho de disco e as farinhas de quinoa integral e arroz polido foram submetidas às respectivas análises de caracterização química.

\subsubsection{Composição centesimal}

Foram efetuadas análises de umidade, extrato etéreo, proteína bruta e cinzas, segundo AOAC (2000), e fibra bruta conforme VAN DE KAMER e VAN GINKEL (1952).

\subsubsection{Composição em minerais}

Realizaram-se as determinações de alumínio, cobalto, cromo, cobre, molibdênio, selênio, zinco, fósforo, cálcio, sódio, magnésio, manganês, ferro e potássio, de acordo com os métodos da AOAC (2000). A quantificação dos minerais foi efetuada em espectrofotômetro de emissão de plasma (ICP Spectroflama), com determinação por espectrometria de emissão atômica, após digestão completa da amostra com ácido nítrico e ácido perclórico.

\subsubsection{Composição em aminoácidos}

As determinações de aparagina, treonina, serina, glutamina, prolina, glicina, alanina, cistina, valina, metionina, isoleucina, leucina, tirosina, fenilalanina, histidina, lisina e arginina foram efetuadas de acordo com os métodos da AOAC (2000). A quantificação desses aminoácidos foi realizada em cromatógrafo a líquido de alta eficiência (CLAE), marca Hewlett Packard, modelo 1090 M.

O escore dos aminoácidos essenciais (EAAE) foi calculado com base nos teores de aminoácidos, tomando-se como referência os padrões recomendados pela FAO/WHO (1991) para crianças de 2 a 5 anos, de 10 a 12 anos e de adultos. 
2.5 PROCESSAMENTO DE OBTENÇÃO DAS MATÉRIASPRIMAS E MACARRÕES PRÉ-COZIDOS

\subsubsection{Obtenção da farinha integral de quinoa e da farinha de arroz polido}

Os grãos de quinoa foram limpos e selecionados manualmente com a utilização de agitador de peneiras. Os grãos de quinoa limpos e selecionados foram pesados e lavados em água potável fria, na proporção de matéria-prima:água de 1:3. Sofreram leve agitação manual para formação de espuma e eliminação da saponina, sendo a água de lavagem renovada até a retirada total da espuma. Após a lavagem e drenagem da água, os grãos de quinoa foram uniformemente distribuídos em bandejas e levados à estufa a $60^{\circ} \mathrm{C}$ até atingir $8,30 \%$ de umidade. Em seguida, os grãos de quinoa e de arroz polido foram moídos em moinho de facas e martelo, com peneira de $1 \mathrm{~mm}$, obtendose então a farinha integral de quinoa e a farinha de arroz polido, respectivamente. Para maior homogeneidade no tamanho de partículas, as farinhas obtidas foram submetidas à análise de classificação granulométrica.

\subsubsection{Classificação granulométrica}

Foram peneiradas $100 \mathrm{~g}$ das farinhas de quinoa e de arroz polido, respectivamente, durante 10 minutos. Usou-se conjunto de sete peneiras arredondadas, vibratórias e com aberturas das malhas variando de 20, 50, 60, 80, 100, 140 a 200 mesh. Em seguida, as quantidades retidas em cada peneira foram pesadas e expressas em percentagens. Com maior homogeneidade no tamanho de partículas, as farinhas de quinoa e arroz foram misturadas na proporção de 60:40 para obtenção da farinha mista de quinoa e arroz.

\subsubsection{Condicionamento da matéria-prima}

A farinha mista de quinoa integral e de arroz polido foi acondicionada a 35\% de umidade de acordo com a seguinte equação:

$$
\mathrm{Y}=\frac{(\mathrm{Uf}-\mathrm{Ui}) \times \mathrm{Pa}}{100-\mathrm{Uf}}
$$


Na qual:

$\mathbf{Y}=$ quantidade de água a ser adicionada $(\mathrm{mL})$.

Uf = umidade final da amostra (\%).

$\mathbf{U i}=$ umidade inicial da amostra (\%).

$\mathbf{P a}=$ peso da amostra $(\mathrm{g})$.

A umidade das amostras foi calculada tendo em vista a umidade inicial da farinha integral de quinoa e da farinha de arroz polido, que apresentaram valores de 8,30\% e 13,40\%, respectivamente.

A amostra acondicionada foi homogeneizada, utilizando-se batedeira industrial com agitação durante 5 minutos, colocada em sacos plásticos e armazenada sob refrigeração durante três horas para se obter distribuição e absorção mais uniformes da água.

\subsubsection{Processo de extrusão}

Iniciou-se a extrusão das amostras após a temperatura das zonas de alimentação, transição e de alta pressão atingirem os valores estabelecidos em ensaios preliminares:

- Temperatura: 60 e $77^{\circ} \mathrm{C}$.

- Taxa de alimentação: $85 \mathrm{~g} /$ minuto.

- Rotação de parafuso: 80 rpm.

- Espessura da matriz: $1 \mathrm{~mm}$.

- Largura da matriz: $1 \mathrm{~cm}$.

- Secagem: $40^{\circ} \mathrm{C} / 1$ hora.

O produto extrusado foi coletado depois de atingir o equilíbrio do processo, sendo, em seguida, cortado em tiras de $15 \mathrm{~cm}$, dispostas em bandejas, colocadas em estufa com circulação de ar a $40^{\circ} \mathrm{C}$ por 1 hora para secar. Decorrido esse período, a estufa foi desligada e o produto mantido em seu interior até alcançar umidade final de aproximadamente $12,50 \%$. O produto foi embalado em sacos plásticos, devidamente etiquetados e armazenados sob temperatura ambiente. Para algumas análises foi necessário moer os extrusados em moinho de disco, obtendo-se a farinha dos macarrões pré-cozidos. 


\section{RESULTADOS E DISCUSSÃO}

\subsection{DISTRIBUIÇÃO DO TAMANHO DE PARTÍCULAS DA FARINHA INTEGRAL DE QUINOA E DA FARINHA DE ARROZ POLIDO}

A característica granulométrica da matéria-prima constitui aspecto importante na elaboração de massas alimentícias, pois a distribuição adequada de partículas permite maior uniformidade no produto elaborado.

Durante a mistura da farinha e da água, partículas mais finas tendem a absorver água mais rapidamente que as grossas, o que exige tempo de mistura mais prolongado para a homogeneização. Desta forma, a distribuição ou regularidade no tamanho das partículas é mais importante que o tamanho propriamente dito.

Observou-se que, aproximadamente 45 e $12 \%$ das partículas na farinha integral de quinoa e 70 e $10 \%$ das partículas da farinha de arroz polido ficaram retidas nas peneiras de 50 e 60 mesh, respectivamente. Por outro lado, verificou-se distribuição relativamente homogênea nas demais peneiras testadas para ambas as farinhas (Tabela 1). Em trabalho semelhante, GARBER e colaboradores (1997) verificaram que a pressão na matriz foi influenciada pela interação de três fatores de processamento: tamanho de partícula, velocidade do parafuso e conteúdo de umidade de condicionamento. Por outro lado, DESRUMAUX et al., (1988) afirmaram que o incremento no tamanho da partícula gera extrusados leves e de estrutura das células maiores. Além disso, maior efeito de cozimento ou transformação do amido ocorreu nas partículas menores.

MOHAMED (1990) constatou que a irregularidade no tamanho de partículas influencia, negativamente, características físicas como dureza e expansão de produtos extrusados.

A homogeneidade no tamanho de partículas promove cozimento adequado e uniforme da matéria-prima durante o processo de extrusão.

Previne a dureza e o cozimento parcial que comprometem a qualidade do produto extrusado, tanto na aparência quanto na palatabilidade (RAMIREZ e WANDERLEI, 1997). 


\section{TABELA 1 - DISTRIBUIÇÃO (\%) DO TAMANHO DE PARTÍCULAS DA FARINHA INTEGRAL DE QUINOA E DA FARINHA DE ARROZ POLIDO}

\begin{tabular}{|c|c|c|c|}
\hline \multirow{2}{*}{$\begin{array}{l}\text { Mesh } \\
\text { (Tyler) }\end{array}$} & \multirow{2}{*}{$\begin{array}{c}\text { Abertura } \\
(\mathrm{mm})\end{array}$} & \multicolumn{2}{|c|}{ MatØria-prima } \\
\hline & & $\begin{array}{c}\text { Farinha integral } \\
\text { de Quinoa (\%) }\end{array}$ & $\begin{array}{c}\text { Farinha de Arroz } \\
\text { polido (\%) }\end{array}$ \\
\hline 20 & 0,850 & 00,00 & 4,60 \\
\hline 50 & 0,300 & 45,58 & 69,70 \\
\hline 60 & 0,250 & 12,35 & 9,70 \\
\hline 80 & 0,180 & 13,01 & 5,85 \\
\hline 100 & 0,150 & 6,76 & 2,15 \\
\hline 140 & 0,106 & 9,93 & 2,80 \\
\hline 200 & 0,075 & 7,05 & 2,65 \\
\hline Fundo $<200$ & Fundo & 5,30 & 2,55 \\
\hline
\end{tabular}

O tamanho das partículas da farinha exerce influência sobre características sensoriais como aparência, sabor, textura e no tempo de cozimento. O processo de moagem inadequado contribui para maior número de partículas heterogêneas na farinha, comprometendo a qualidade final dos produtos elaborados (LINDEN e LORIENT, 1994). Maior uniformidade no tamanho de partículas de farinhas é importante na elaboração de produtos intermediários por extrusão, como macarrões pré-cozidos, cujo processo exige altas percentagens de umidade (menor fricção no interior do extrusor) e conseqüente redução na transformação da estrutura amilácea.

\subsection{QUALIDADE DOS MACARRÕES PRÉ-COZIDOS À BASE DE FARINHA INTEGRAL DE QUINOA E DE FARINHA DE ARROZ POLIDO}

Ambos os macarrões pré-cozidos, avaliados no estado seco e cru, mostraram uniformidade em termos de comprimento $(15 \mathrm{~cm})$, espessura $(1 \mathrm{~mm})$ e largura $(1 \mathrm{~cm})$. Apresentaram-se lisos, sem rugosidade e de coloração uniforme. De acordo com DEXTER, MATSUO e MORGAN (1981), WALSH e GILLES (1974) tais características de qualidade são fundamentais no aspecto comercial do produto. 
A Tabela 2 apresenta as principais características de qualidade dos macarrões pré-cozidos e, em caráter comparativo, os resultados obtidos com macarrão comercial tipo talharim.

\section{TABELA 2 - RESULTADOS (\% BASE SECA) DO TESTE DE QUALIDADE DOS MACARRÕES PRÉ-COZIDOS A 60 E $77^{\circ} \mathrm{C}$ E DE MACARRÃO PADRÃO}

\begin{tabular}{ccccccccc}
\hline $\begin{array}{c}\text { Macarr } \mathbf{a} \\
\text { prø-cozido }\end{array}$ & $\begin{array}{c}\text { Tempo } \\
\text { cozim. } \\
\text { (min.) }\end{array}$ & $\begin{array}{c}\text { AP } \\
(\%)\end{array}$ & $\begin{array}{c}\text { AV } \\
(\%)\end{array}$ & $\begin{array}{c}\text { SS } \\
(\%)\end{array}$ & $\begin{array}{c}\mathbf{R} \\
(\%)\end{array}$ & $\begin{array}{c}\text { D1 } \\
\left(\mathbf{g} / \mathbf{c m}^{3}\right)\end{array}$ & $\begin{array}{c}\text { D2 } \\
\left(\mathbf{g} / \mathbf{c m}^{3}\right)\end{array}$ & $\begin{array}{c}\text { AA } \\
(\mathbf{m L})\end{array}$ \\
\hline $60^{\circ} \mathrm{C}$ & 5 & 49,92 & 150 & 9,32 & 202,90 & 1,44 & 1,17 & 3,30 \\
$77^{\circ} \mathrm{C}$ & 7 & 49,95 & 120 & 7,72 & 198,50 & 1,33 & 1,20 & 2,10 \\
$\begin{array}{c}\text { Macarr } \\
\text { padr } 0^{*}\end{array}$ & 12 & 59,18 & 266 & 2,27 & 245 & 1,67 & 1,11 & 2,50 \\
\hline
\end{tabular}

*Tipo talharim à base de trigo.

$\mathrm{AP}=$ Aumento de Peso (\%).

$\mathrm{R}=$ Rendimento (\%).

$\mathrm{AV}=$ Aumento de Volume (\%).

D1 = Densidade do produto $\mathrm{cru}\left(\mathrm{g} / \mathrm{cm}^{3}\right)$.

SS = Sólidos Solúveis (\%).

D2 = Densidade do produto cozido $\left(\mathrm{g} / \mathrm{cm}^{3}\right)$.

$\mathrm{AA}=$ Acidez Alcoólica $(\mathrm{mL})$.

O tempo de cozimento dos macarrões pré-cozidos correspondeu a aproximadamente metade do tempo de cozimento do macarrão tipo talharim, o que oferece grande vantagem com relação às etapas de pré-preparo e preparo do prato. Valores próximos também foram obtidos com relação ao AP (\%), R (\%), D1 $\left(\mathrm{g} / \mathrm{cm}^{3}\right)$, D2 $\left(\mathrm{g} / \mathrm{cm}^{3}\right)$ e AA $(\mathrm{mL})$.

O resultado da análise de AV (\%) revelou valor bastante baixo, entretanto, o oposto foi observado com relação aos SS (\%). Tais resultados podem ser atribuídos às características intrínsecas de cada matéria-prima utilizada na obtenção dos macarrões pré-cozidos. Além disso, durante o processo de extrusão termoplástica ocorreu précozimento da mistura de farinha integral de quinoa e da farinha de arroz polido, ao contrário do sistema convencional.

Com relação às características intrínsecas das matérias-primas, acredita-se que a ausência de glúten possa ter influenciado nos resultados obtidos. O glúten confere à massa propriedades tecnológicas como elasticidade, coesividade, hidratação, conformação e tamanho molecular, contribuindo assim para aumento no rendimento, redução no teor de sólidos solúveis e firmeza em água quente, embora favoreça o aumento do tempo de cozimento. 
3.3 CARACTERIZAÇÃO QUÍMICA DA FARINHA INTEGRAL DE QUINOA, DA FARINHA DE ARROZ POLIDO E DE MACARRÕES PRÉ-COZIDOS

\subsubsection{Composição centesimal}

A Tabela 3 mostra, em base seca, a composição centesimal aproximada da farinha integral de quinoa, da farinha de arroz polido e de macarrões pré-cozidos antes do cozimento.

\section{TABELA 3 - COMPOSIÇÃO CENTESIMAL APROXIMADA (\% BASE SECA) DA FARINHA INTEGRAL DE QUINOA, DA FARINHA DE ARROZ POLIDO E DE MACARRÕES PRÉ- COZIDOS}

\begin{tabular}{lcccc}
\hline Composi a o (\%) & $\begin{array}{c}\text { Farinha integral } \\
\text { de quinoa (\%) }\end{array}$ & $\begin{array}{c}\text { Farinha de arroz } \\
\text { polido (\%) }\end{array}$ & \multicolumn{2}{c}{ Macarra o prø-cozido } \\
\cline { 4 - 5 } & 17,37 & 7,50 & $\mathbf{6 0} \mathbf{C}$ & $\mathbf{7 7}{ }^{\circ} \mathbf{C}$ \\
\hline Prote na & 3,96 & 0,30 & 11,97 & 11,05 \\
Extrato etØreo & 2,39 & 0,57 & 0,91 & 0,79 \\
Cinzas & 4,47 & 1,62 & 2,23 & 2,22 \\
Fibra bruta & 71,81 & 77,33 & 85,35 & n.d. \\
Carboidrato $^{1}$ & & & & \\
\hline
\end{tabular}

${ }^{1}$ Calculado por diferença (100 - proteína - extrato etéreo - fibra bruta) n.d = não-determinado.

A maioria das frações (proteína, extrato etéreo, cinzas, fibra bruta) apresentou valores mais altos para a farinha integral de quinoa do que para a farinha de arroz polido, devido tratar-se de matéria-prima integral. O oposto foi verificado com relação ao teor de carboidratos em razão do arroz branco polido ser constituído, basicamente, pelo endosperma amiláceo. Valores similareres foram encontrados por FRANCO (1996) para as duas farinhas, embora o teor de proteína da farinha integral de quinoa obtido no presente trabalho tenha revelado aumento de $50 \%$. Resultados semelhantes para a composição centesimal da quinoa foram também encontrados por RUALES e NAIR (1992), os quais consideram que essa matéria-prima apresenta qualidade protéica superior à maioria dos cereais comuns. $O$ teor de cinzas da farinha integral de quinoa (2,39\%, base seca) mostrou-se aproximadamente quatro vezes maior que o valor encontrado para a farinha de arroz 
polido $(0,57 \%$, base seca), permanecendo alto nos macarrões précozidos $(2,23$ e 2,22\%). Tais valores são superiores aos recomendados por LEITÃO et al. (1990) para massa alimentícia, à base de trigo, de boa qualidade $(0,50-0,70 \%)$. O fato de se usar farinha de quinoa integral implica em valores altos no teor de cinzas, que no produto final poderá variar segundo a percentagem de quinoa/arroz utilizada no seu preparo. O teor de cinzas está diretamente relacionado à coloração que a massa alimentícia apresenta no estado cru.

GOMES (1999) constatou que a composição centesimal de variedades de quinoa, cultivadas nos solos brasileiros não diferem daquelas cultivadas nos países andinos (região de origem do cereal).

\subsubsection{Composição em minerais}

A Tabela 4 apresenta a composição em minerais da farinha integral de quinoa, da farinha de arroz polido e de macarrões pré-cozidos. Os minerais fósforo, cálcio, sódio, magnésio, ferro e potássio evidenciaram maiores teores, verificando-se pequenas quantidades ou apenas traços dos demais minerais.

Quantidades mais elevadas da maioria dos minerais foram observadas na farinha integral de quinoa em relação à farinha de arroz polido. Isso significa que, sob o ponto de vista nutricional, é mais indicado processar os grãos na forma integral devido ao aumento de minerais na dieta. ASCHERI, RAMIREZ-ASCHERI e CARVALHO (1998) afirmaram que a composição em minerais da quinoa integral a coloca como fonte inquestionável de minerais, apresentando valores superiores ao grits de milho e ao arroz polido extrusados.

O teor de fósforo na quinoa integral $(372,12 \mathrm{mg} / 100 \mathrm{~g})$ coloca esse produto em evidência quando comparado ao arroz polido $(78 \mathrm{mg} /$ $100 \mathrm{~g})$. Os valores encontrados nos macarrões pré-cozidos $(194,72 \mathrm{e}$ $191,74 \mathrm{mg} / 100 \mathrm{~g})$ podem suprir, respectivamente, $25 \% \mathrm{da}$ recomendação diária (RDA) para crianças de 4 a 10 anos (NRC, 1989). A quinoa pode contribuir para o suprimento de fósforo na dieta, o qual é importante para inúmeras funções orgânicas e para a estrutura de ossos e dentes. Constitui, ainda, componente de ácidos nucléicos, fosfolipídios, membrana celular e conjugados protéicos, entre outros (MAHAN e ESCOTT-STUMP, 1998). 


\section{TABELA 4 - COMPOSIÇÃO EM MINERAIS (mg/100 g, BASE SECA) DA FARINHA INTEGRAL DE QUINOA, FARINHA DE ARROZ POLIDO E MACARRÕES PRÉ-COZIDOS}

\begin{tabular}{|c|c|c|c|c|}
\hline \multirow[t]{2}{*}{ Mineral } & \multirow{2}{*}{$\begin{array}{l}\text { Farinha integral } \\
\text { de quinoa }\end{array}$} & \multirow{2}{*}{$\begin{array}{l}\text { Farinha de } \\
\text { arroz polido }\end{array}$} & \multicolumn{2}{|c|}{ Macarra o prø-cozido } \\
\hline & & & $60^{\circ} \mathrm{C}$ & $77^{\circ} \mathrm{C}$ \\
\hline Alum nio & 3,03 & n.d. & 1,27 & 2,64 \\
\hline Cobalto & n.d. & 0,06 & n.d. & n.d. \\
\hline Cromo & 0,02 & n.d. & n.d. & n.d. \\
\hline Cobre & 0,36 & n.d. & 0,32 & 0,33 \\
\hline MolibdCfrio & 0,03 & 0,13 & n.d. & n.d. \\
\hline SelCfrio & 0,01 & 0,07 & 0,06 & 0,05 \\
\hline Zinco & 4,02 & 1,46 & 2,45 & 2,25 \\
\hline F sforo & 372,12 & 78,79 & 194,72 & 191,74 \\
\hline C AEcio & 73,19 & 6,51 & 33,66 & 29,70 \\
\hline$S$ dio & 3,74 & 9,27 & 392,34 & 368,42 \\
\hline MagnØsio & 228,15 & 53,92 & 112,23 & 115,47 \\
\hline Mangands & 2,67 & 0,91 & 1,89 & 1,51 \\
\hline Ferro & 5,82 & 4,81 & 4,54 & 6,55 \\
\hline Pot/Essio & 570,70 & 99,62 & 269,47 & 253,16 \\
\hline
\end{tabular}

n.d. = não-detectado .

Outro elemento importante, com valor considerável na quinoa integral, é o cálcio (73,19 mg/100 g), quando comparado ao valor encontrado no arroz polido $(6,51 \mathrm{mg} / 100 \mathrm{~g})$. Segundo OLIVEIRA, SANTOS e WILSON (1982); FRANCO (1996) e WILLIANS (1997) o cálcio, juntamente com o fósforo, apresenta como função primária a formação de ossos e dentes. Entretanto, o equilíbrio entre esses minerais no organismo humano pode variar conforme a faixa etária e o estado fisiológico.

O teor de sódio mostrou-se bastante baixo em ambas as farinhas quando comparado aos teores presentes nos macarrões pré-cozidos (392,34 e 368,42 mg/100 g, respectivamente). Tal fato deve-se ao sal (1\%) adicionado à formulação dos macarrões. Entretanto, os teores de sódio encontrados nesses macarrões podem atender, respectivamente, 98 e $92 \%$ da RDA para crianças de 6 a 9 anos, e 78 e $73 \%$ para indivíduos acima de 18 anos (NRC, 1989). 
Os teores de magnésio verificados nos macarrões pré-cozidos $(112,23$ e $115,47 \mathrm{mg} / 100 \mathrm{~g})$ podem suprir $95 \%$ da RDA para crianças de 4 a 6 anos, $67 \%$ para crianças de 7 a 10 anos e $40 \%$ para préadolescentes de 11 a 14 anos (NRC, 1989). Já os teores de ferro $(4,54$ e $6,55 \mathrm{mg} / 100 \mathrm{~g}$ ) atendem, respectivamente, 45 e $66 \%$ da RDA para crianças de 7 a 10 anos e homens de 25 a 50 anos (NRC, 1989). O ferro constitui parte essencial da hemoglobina e sua deficiência tem como conseqüência a anemia ferropriva, causada, principalmente, pela ingestão insuficiente ou má absorção desse mineral.

O potássio presente na farinha integral de quinoa correspondeu a seis vezes o valor verificado na farinha de arroz polido. Os teores encontrados nos macarrões pré-cozidos $(269,47$ e $253,16 \mathrm{mg} / 100 \mathrm{~g})$, respectivamente, correspondem a 17 e $16 \%$ da RDA para crianças de 6 a 9 anos e 13 e 12\% para indivíduos acima de 10 anos (NRC, 1989). Esse mineral, juntamente com o sódio e o cálcio, auxilia a estimulação neuromuscular, a transmissão de impulsos eletroquímicos e a contração muscular. Sua deficiência ocasiona doenças gastrointestinais, diarréia, desequilíbrio hídrico e ácido-básico, entre outros (HENDLER, 1994; WILLIANS, 1997; MAHAN e ESCOTTSTUMP, 1998).

Os teores da maioria dos outros minerais essenciais (alumínio, cobalto, cromo, cobre molibdênio, selênio, zinco e manganês) mostraram-se mais altos na farinha integral de quinoa, não variando muito nos macarrões pré-cozidos. Por outro lado, os minerais cobalto, cromo e molibdênio com teores zero ou quase zero em ambas as farinhas, não foram encontrados nos macarrões pré-cozidos.

\subsubsection{Composição em aminoácidos}

Verificou-se que a farinha integral de quinoa apresentou valores superiores para a maioria dos aminoácidos analisados quando comparada à farinha de arroz polido (Tabela 5). Resultados semelhantes foram encontrados por ASCHERI, RAMIREZ-ASCHERI e CARVALHO (1998) em farinha integral instantânea de quinoa extrusada. O conteúdo de lisina na farinha integral de quinoa é aproximadamente o dobro do obtido para a farinha de arroz polido, cujos valores são superiores aos verificados por FRANCO (1996) para arroz, aveia, trigo e milho. Com 
relação ao arroz, os teores encontrados mostraram-se semelhantes aos valores descritos por SGARBIERI (1996).

\section{TABELA 5 - COMPOSIÇÃO EM AMINOÁCIDOS (g/16 g N) DA FARINHA INTEGRAL DE QUINOA, DA FARINHA DE ARROZ POLIDO E DE MACARRÕES PRÉ-COZIDOS}

\begin{tabular}{|c|c|c|c|c|}
\hline \multirow{2}{*}{ Am ino AEcido } & \multirow{2}{*}{$\begin{array}{c}\text { Farinha integral } \\
\text { de quinoa }\end{array}$} & \multirow{2}{*}{$\begin{array}{l}\text { Farinha de } \\
\text { arroz polido }\end{array}$} & \multicolumn{2}{|c|}{ Macarra o prø-cozido } \\
\hline & & & $60^{\circ} \mathrm{C}$ & $77^{\circ} \mathrm{C}$ \\
\hline Asparagina & 9,70 & 9,87 & 6,01 & 8,78 \\
\hline Treonina & 4,30 & 3,33 & 3,43 & 5,34 \\
\hline Serina & 4,80 & 4,27 & 3,43 & 5,52 \\
\hline Glutamina & 35,10 & 21,87 & 13,78 & 21,27 \\
\hline Prolina & 2,31 & 0,13 & 3,17 & 3,85 \\
\hline Glicina & 4,20 & 2,13 & 3,17 & 5,25 \\
\hline Alanina & 4,90 & 4,93 & 3,51 & 4,89 \\
\hline Cistina & 1,03 & 1,73 & 0,33 & 0,45 \\
\hline Valina & 4,62 & 5,10 & 3,17 & 4,43 \\
\hline Metionina & 1,54 & 1,47 & 1,25 & 1,63 \\
\hline Isoleucina & 4,20 & 3,60 & 2,26 & 3,44 \\
\hline Leucina & 6,93 & 6,80 & 5,43 & 7,06 \\
\hline Tirosina & 3,08 & 3,60 & 2,51 & 2,81 \\
\hline Fenilalanina & 4,11 & 4,27 & 3,17 & 4,16 \\
\hline Histidina & 3,60 & 2,27 & 1,84 & 3,17 \\
\hline Lisina & 4,45 & 2,27 & 2,17 & 3,53 \\
\hline Arginina & 7,45 & 5,07 & 4,76 & 7,51 \\
\hline
\end{tabular}

Os teores de aminoácidos nos macarrões pré-cozidos sugerem efeito complementar mútuo entre a farinha integral de quinoa e farinha de arroz polido, contribuindo para a melhoria do valor nutricional de ambos os macarrões pré-cozidos obtidos.

Os escores de aminoácidos essenciais da farinha integral de quinoa, da farinha de arroz polido e de macarrões pré-cozidos encontram-se nas Tabelas 6, 7 e 8.

Verifica-se pela Tabela 6, que a farinha integral de quinoa, a farinha de arroz polido e os macarrões pré-cozidos apresentaram valores inferiores de escore de lisina. Já na Tabela 7, pode-se constatar que a farinha de arroz polido e os macarrões pré-cozidos revelaram valores inferiores desse aminoácido, quando comparados com os demais aminoácidos essenciais. A lisina foi considerada como limitante para crianças de 2 a 5 e 10 a 12 anos, de acordo com as recomendações 
da FAO/WHO (1991). Entretanto, a farinha integral de quinoa não apresentou nenhum aminoácido limitante para crianças de 10 a 12 anos.

Pode ser constatado ainda (Tabelas 6, 7 e 8) que os aminoácidos sulfurados (metionina + cistina) apresentaram escore mais baixo no macarrão pré-cozido a $60^{\circ} \mathrm{C}$ e que o macarrão pré-cozido a $77^{\circ} \mathrm{C}$ revelou valores superiores para todos aminoácidos essenciais analisados. Desta forma, a temperatura de extrusão contribuiu para aumentar o valor nutricional dos macarrões obtidos.

\section{TABELA 6 - ESCORES DE AMINOÁCIDOS ESSENCIAIS (\%) DA FARINHA INTEGRAL DE QUINOA, DA FARINHA DE ARROZ POLIDO E DE MACARRÕES PRÉ-COZIDOS PARA CRIANÇAS DE 2 A 5 ANOS}

\begin{tabular}{|c|c|c|c|c|}
\hline \multirow{2}{*}{ Amino feido } & \multirow{2}{*}{$\begin{array}{c}\text { Farinha integral } \\
\text { de quinoa }\end{array}$} & \multirow{2}{*}{$\begin{array}{l}\text { Farinha de } \\
\text { arroz polido }\end{array}$} & \multicolumn{2}{|c|}{ Macarra o prø-cozido } \\
\hline & & & $60^{\circ} \mathrm{C}$ & $77^{\circ} \mathrm{C}$ \\
\hline Isoleucina & 150 & 129 & 81 & 123 \\
\hline Leucina & 105 & 103 & 82 & 107 \\
\hline Lisina & 77 & 39 & 37 & 61 \\
\hline Metionina+cistina & 103 & 128 & 63 & 83 \\
\hline Fenilalanina+tirosina & 114 & 125 & 90 & 111 \\
\hline Treonina & 126 & 98 & 101 & 157 \\
\hline Valina & 132 & 146 & 91 & 127 \\
\hline Histidina & 189 & 119 & 97 & 167 \\
\hline
\end{tabular}

O tratamento térmico favorece o aumento do valor nutricional de produtos alimentícios, devido à desnaturação de proteínas e melhoria nas características sensoriais (textura, sabor, cor, aparência), além de inativar enzimas, fatores antinutricionais e microrganismos. A proteína desnaturada é mais sensível à hidrólise pelas enzimas proteolíticas e, portanto, sua digestibilidade e utilização aumentam. Segundo afirma SGARBIERI (1996), propriedades nutricionais como digestibilidade, biodisponibilidade de aminoácidos e valor biológico, são melhoradas pela desnaturação.

Não foi verificado aminoácido limitante para adultos nas farinhas analisadas e macarrões pré-cozidos, sendo capazes de atender acima de $90 \%$ das recomendações da FAO/WHO (1991) de todos os aminoácidos essenciais (Tabela 8). 


\section{TABELA 7 - ESCORES DE AMINOÁCIDOS ESSENCIAIS (\%) DA FARINHA INTEGRAL DE QUINOA, DA FARINHA DE ARROZ POLIDO E DE MACARRÕES PRÉ-COZIDOS PARA CRIANÇAS DE 10 A 12 ANOS}

\begin{tabular}{|c|c|c|c|c|}
\hline \multirow[t]{2}{*}{ Amino Ecido } & \multirow{2}{*}{$\begin{array}{l}\text { Farinha integral } \\
\text { de quinoa }\end{array}$} & \multirow{2}{*}{$\begin{array}{l}\text { Farinha de } \\
\text { arroz polido }\end{array}$} & \multicolumn{2}{|c|}{ Macarra o prø-cozido } \\
\hline & & & $60^{\circ} \mathrm{C}$ & $77^{\circ} \mathrm{C}$ \\
\hline Isoleucina & 150 & 129 & 81 & 123 \\
\hline Leucina & 158 & 155 & 123 & 160 \\
\hline Lisina & 101 & 52 & 49 & 80 \\
\hline Metionina+cistina & 117 & 145 & 72 & 95 \\
\hline Fenilalanina+tirosina & 327 & 358 & 258 & 317 \\
\hline Treonina & 154 & 119 & 123 & 191 \\
\hline Valina & 185 & 204 & 127 & 177 \\
\hline Histidina & 189 & 119 & 97 & 167 \\
\hline
\end{tabular}

\section{TABELA 8 - ESCORES DE AMINOÁCIDOS ESSENCIAIS (\%) DA FARINHA INTEGRAL DE QUINOA, DA FARINHA DE ARROZ POLIDO E DE MACARRÕES PRÉ-COZIDOS PARA ADULTOS}

\begin{tabular}{|c|c|c|c|c|}
\hline \multirow[t]{2}{*}{ Amino AEido } & \multirow{2}{*}{$\begin{array}{l}\text { Farinha integral } \\
\text { de quinoa }\end{array}$} & \multirow{2}{*}{$\begin{array}{l}\text { Farinha de } \\
\text { arroz polido }\end{array}$} & \multicolumn{2}{|c|}{ Macarra o prø-cozido } \\
\hline & & & $60^{\circ} \mathrm{C}$ & $77^{\circ} \mathrm{C}$ \\
\hline Isoleucina & 323 & 277 & 174 & 265 \\
\hline Leucina & 365 & 358 & 286 & 372 \\
\hline Lisina & 278 & 142 & 136 & 221 \\
\hline Metionina+cistina & 151 & 188 & 93 & 122 \\
\hline Fenilalanina+tirosina & 378 & 414 & 299 & 367 \\
\hline Treonina & 478 & 370 & 381 & 593 \\
\hline Valina & 355 & 392 & 244 & 341 \\
\hline Histidina & 327 & 206 & 167 & 288 \\
\hline
\end{tabular}

\section{CONCLUSÃO}

A homogeneidade no tamanho de partículas das matérias-primas permitiu a obtenção de produto uniforme e adequadamente cozido durante o processo de extrusão. Os macarrões pré-cozidos apresentaram tempo de cozimento correspondente à metade do tempo 
de cozimento do macarrão comercial tipo talharim. A farinha integral de quinoa apresentou valores superiores de proteína, extrato etéreo, cinzas e fibra bruta, quando comparada à farinha de arroz polido. Entretanto, o alto teor de cinzas encontrado (juntamente com outros fatores relacionados à matéria-prima integral) pode ter promovido incremento no escurecimento do produto final com o aumento do teor de farinha integral de quinoa na formulação. A farinha integral de quinoa apresentou valores superiores para os diferentes minerais analisados, quando comparada à farinha de arroz polido, sendo o fósforo, o cálcio, o magnésio, o ferro e o potássio, os que mais se destacaram em ambas as farinhas. Os teores encontrados nos macarrões pré-cozidos podem contribuir para o suprimento das recomendações diárias estabelecidas para diferentes faixas etárias. A farinha integral de quinoa apresentou os maiores teores para os diferentes aminoácidos analisados, quando comparada à farinha de arroz polido. O escore de aminoácidos essenciais para as matérias-primas e macarrões précozidos permitiu constatar que a lisina é o aminoácido limitante em ambas as matérias-primas, em macarrões pré-cozidos para crianças de 2 a 5 anos e na farinha de arroz polido e macarrões pré-cozidos para crianças de 10 a 12 anos. Não foi encontrado aminoácido limitante para adultos.

\section{Abstract \\ COOKING PROPERTIES AND PHYSICO-CHEMICAL CHARACTERIZATION OF PRECOOKED MACARONI OF WHOLE QUINOA (Chenopodium quinoa, WILLD) FLOUR AND RICE (Orysa sativa, L) FLOUR BY EXTRUSION COOKING}

The present research had as objective to analyze the cooking properties and to study the physico-chemical characteristics of precooked macaroni of quinoa whole flour (Chenopodium quinoa, Willd) and rice (Oryza sativa, L) flour obtained by extrusion cooking. The precooked macaroni, due to intrinsic characteristics of the raw material, compared to traditional macaroni of wheat flour, presented lower values of weight increase (\%), volume Increase (\%), yield (\%) and density of raw product $\left(\mathrm{g} / \mathrm{cm}^{3}\right)$ and higher values of soluble solids (\%). The results of this study allowed to identify that whole quinoa possesses higher values for different accomplished analyses (proximal composition, minerals and amino acids profile). The score of essential amino acids for the raw materials and precooked macaroni, according to recommendations of FAO/WHO (1991), allowed to verify that the lysin is a limitant amino acid in both raw materials and in precooked macaroni for children from 2 to 5 years and in the rice flour and precooked macaroni for children from 10 to 12 years. It was not found limitant amino acid for adults. 
KEY-WORDS: GLUTEN-FREE MACARONI; QUINOA-FLOUR; RICE-FLOUR; EXTRUSION-COOKING.

\section{REFERÊNCIAS}

1 ASCHERI, J. L. R.; RAMIREZ-ASCHERI, E.; CARVALHO, C. W. P. Elaboracion de harina integral instantanea de quinua (Chenopodium quinoa, Willd) por extrusion termoplástica. Alimentaria, Madrid, n.292, p.93-98, Mayo 1998.

2 AOAC. Association of Official Analytical Chemists. Official methods of analysis of the AOAC International. 17 $7^{\text {th }}$ ed. Gaithersburg, 2000.

3 CHAUHAN, G. S.; ZILLMAN, R. R. ESKIN, M. N. A. Dough mixing and bread making properties of quina wheat flour blends. International Journal of Food Science \& Technology, Mysore, v.27, p. 701-705, 1992.

4 CIACCO, C. F.; CHANG, Y. K. Como fazer massas. São Paulo: Ícone, 1986. $127 \mathrm{p}$.

5 DESRUMAUX, A. ; BOUVIER, J.M.; BURRI. J. Corn grits particle size and distribuition effects on the characteristichs of expanded extrudates. Journal of Food Science, Chicago, v.63, n.5, p.857-863, 1988.

6 DEXTER, J. E.; MATSUO, R. R.; MORGAN, B. C. High temperature drying: Effect on spaghetti properties. Journal of Food Science, Chicago, v.46, n.6, p.17411746, 1981.

7 FAO/WHO. Food and Agriculture Organization of the United Nations/World Health Organization. Protein quality evaluation: report of joint FAO/WHO expert consultation. Rome, 1991.

8 FRANCO, G. Tabela de composição química dos alimentos. 9.ed. São Paulo: Atheneu, 1996. 307 p.

9 GARBER, B.W.; HSIEH, F.; HUFF, H.E. Influency of particle size on the twinscrew extrusion of corn meal. Cereal Chemistry, St. Paul, v.74, n.5, p.656$661,1997$.

10 GOMES, M. P. Avaliação do conteúdo organo-mineral de grãos de quinoa (Chenopodium quinoa, Willd). Rio de Janeiro, 1999. 60 p. Tese (Mestrado em Ciência e Tecnologia de Alimentos), Universidade Federal Rural do Rio de Janeiro (UFRRJ).

11 HENDLER, S. S. A enciclopédia de vitaminas e minerais. 5.ed. Rio de Janeiro: Campus, 1994. 576 p. 
12 LEITÃO, R. F. F.; GONÇALVES, J. R.; EIROA, M. N. U.; GARCIA, E. E. C. Tecnologia de macarrão. Campinas: Tecnologia de Alimentos, 1990. 71 p.

13 LEITÃO, R. F. F.; VITTI, P.; ANGELUCCI, E.; YOKOMIZO, Y. Determinações das características mais importantes dos macarrões comerciais. Boletim do ITAL, Campinas, v.38, p.63-76, junho 1974.

14 LINDEN, G.; LORIENT, D. Bioquímica agroindustrial. España (Zaragoza): Acribia, 1994. 426 p.

15 MAHAN, L.K.; ESCOTT-STUMP, S. KRAUSE: alimentos, nutrição e dietoterapia. 9. ed. São Paulo: Roca, 1998. 1179 p.

16 MOHAMED, S. Factors affecting extrusion characteristics of expanded starchbased products. Journal of Food Processing Preservation, Westport, v.14, p.437-452, 1990.

17 NRC. National Research Council. Recommended dietary allowances. $10^{\text {th }}$ ed. Washington: National Academy Press, 1989. 284 p.

18 OLIVEIRA, J. E. D.; SANTOS, A. C.; WILSON, E. D. Nutrição básica. São Paulo: Sarvier, 1982. 286 p.

19 RAMIREZ, J. L. A.; WANDERLEI, C. Efecto de los parámetros de extrusion, características de pasta y textura de pellets (snacks de tercera geracion) producidos a partir de trigo e maiz. Alimentaria, Madrid, v.35, n.279, p.93-98, Enero/Febrero 1997.

20 RUALES, J.; NAIR, B. M. Nutritional quality of the proteins in quinoa (Chenopodium quinoa, Willd). Plant Foods Human Nutrition, New York, v.42, p.1-11, 1992.

21 SGARBIERI, V. C. Proteínas em alimentos protéicos: propriedadesdegradações-modificações. São Paulo: Varela, 1996. 517 p.

22 VAN DE KAMER, J. H.; VAN GINKEL, L. Rapid determination of crude fiber in cereals. Cereal Chemistry, St. Paul, v.29, n.4, p.239-251, July/August 1952.

23 WALSH, D. E.; GILLES, K. A. Macaroni production. In: INGLETT, G. (Ed.). Wheat: production and utilization. Westport: AVI, 1974. p.333-354.

24 WILLIANS, S. R. Minerais. In: FUNDAMENTOS de nutrição e dietoterapia. 6.ed. Porto Alegre: Artes Médicas, 1997. p.144-173. 